\title{
Response to myocardial ischemia/reperfusion injury involves Bnip3 and autophagy
}

\author{
A Hamacher-Brady ${ }^{1}$, NR Brady ${ }^{1}$, SE Logue ${ }^{2}$, MR Sayen ${ }^{1}$, M Jinno $^{1}$, LA Kirshenbaum ${ }^{3}$, RA Gottlieb ${ }^{1}$ and ÅB Gustafsson ${ }^{\star, 1}$
}

Ischemia and reperfusion (I/R) injury is associated with extensive loss of cardiac myocytes. Bnip3 is a mitochondrial proapoptotic Bcl-2 protein which is expressed in the adult myocardium. To investigate if Bnip3 plays a role in I/R injury, we generated a TAT-fusion protein encoding the carboxyl terminal transmembrane deletion mutant of Bnip3 (TAT-Bnip3 $\Delta$ TM) which has been shown to act as a dominant negative to block Bnip3-induced cell death. Perfusion with TAT-Bnip3 $\Delta$ TM conferred protection against I/R injury, improved cardiac function, and protected mitochondrial integrity. Moreover, Bnip3 induced extensive fragmentation of the mitochondrial network and increased autophagy in HL-1 myocytes. 3D rendering of confocal images revealed fragmented mitochondria inside autophagosomes. Enhancement of autophagy by ATG5 protected against Bnip3-mediated cell death, whereas inhibition of autophagy by ATG5K130R enhanced cell death. These results suggest that Bnip3 contributes to I/R injury which triggers a protective stress response with upregulation of autophagy and removal of damaged mitochondria.

Cell Death and Differentiation (2007) 14, 146-157. doi:10.1038/sj.cdd.4401936; published online 28 April 2006

Myocardial ischemia and reperfusion (I/R) triggers cell death via both necrosis and apoptosis. Irreversible loss of cardiac myocytes may lead to reduced ability to sustain contractile function and progression to heart failure. Necrosis is characterized by swelling of the cell and its organelles, and disruption of the cell membrane. ${ }^{1}$ Release of intracellular components into the surrounding tissue leads to activation of an inflammatory response and can cause damage to neighboring cells. In contrast, apoptosis is a highly regulated, energy-dependent cell death program, which leads to elimination of the cell without inducing an inflammatory response. Apoptosis has been implicated in the pathogenesis of several cardiovascular diseases, including myocardial infarction $^{2}$ and congestive heart failure. ${ }^{3}$ Even though it is clear that loss of cardiac myocytes after I/R contributes to the decline of ventricular function and mortality, the relative contribution of apoptotic versus necrotic cell death are a subject of much debate. An increased understanding of the signaling pathways that are activated during $\mathrm{I} / \mathrm{R}$ is important to the development of effective therapies.

Bnip3 is a member of the 'BH3-only' subfamily of proapoptotic $\mathrm{Bcl}-2$ family proteins. The $\mathrm{BH} 3$ domain is essential for the cell death activity of these proteins, as well as for mediating heterodimerization with anti- or proapoptotic proteins which regulate cell death. ${ }^{4}$ Conflicting reports indicate that the apoptotic effects of Bnip3 either depend upon $^{5}$ or are independent of the $\mathrm{BH} 3$ domain. ${ }^{6} \mathrm{Bnip} 3$ is unique in that it possesses a C-terminal transmembrane domain that is required for mitochondrial targeting as well as its apoptotic function. ${ }^{5,7}$ Although Bnip3 mRNA can be detected in multiple organs, ${ }^{7}$ its physiological function is unknown. Elevated Bnip3 protein levels have been observed in vivo in an animal model of chronic heart failure. ${ }^{8}$ Moreover, Bnip3 expression has been reported to be upregulated in neonatal myocytes subjected to hypoxia resulting in mitochondrial dysfunction and subsequent cell death ${ }^{8-10}$ Bnip3 has been demonstrated to induce both necrotic and apoptotic cell death. ${ }^{10,11}$

Recently, upregulation of Bnip3 was reported to correlate with the induction of autophagy in malignant glioma cells. ${ }^{12}$ Autophagy plays an important role in cellular homeostasis and is the process by which cells recycle cytoplasm and dispose of excess or damaged organelles. Autophagy also plays an important role in the cellular response to stress and can be upregulated by changes in environmental conditions such as nutrient deprivation. ${ }^{13}$ Autophagy has been implicated to play a role in cancer, ${ }^{14}$ cardiomyopathy, ${ }^{15}$ and neurodegenerative diseases. ${ }^{16}$ In the present study, we have examined the role of the mitochondrial proapoptotic protein Bnip3 in I/R injury. We provide evidence that Bnip3 contributes to I/R injury in the ex vivo heart. Moreover, we report that simulated I/R leads to Bnip3-mediated upregulation of autophagy in $\mathrm{HL}-1$ cardiac myocytes and that Bnip3-induced mitochondrial dysfunction correlates with upregulation of autophagy as a protective response to remove damaged mitochondria.

\section{Results}

Expression of Bnip3 in adult myocardium. We examined Bnip3 expression in rat hearts and found substantial basal

${ }^{1}$ Department of Molecular and Experimental Medicine, The Scripps Research Institute, La Jolla, CA, USA; ${ }^{2}$ Department of Biochemistry, National University of Ireland, Galway, Ireland and ${ }^{3} \mathrm{St}$ Boniface General Hospital Research Center, Winnipeg, Canada

${ }^{*}$ Corresponding author: ÅB Gustafsson, Department of Molecular and Experimental Medicine, The Scripps Research Institute, MEM 220, 10550 N. Torrey Pines Road, CA 92037, USA. Tel: + 1-858-784-9166; Fax: + 1-858-784-8389; E-mail: agustafs@ scripps.edu

Keywords: Bnip3; ischemia; reperfusion; apoptosis; autophagy; mitochondria

Abbreviations: TUNEL, terminal deoxynucleotideyltransferase-mediated dUTP nick end-labeling; AIF, apoptosis-inducing factor; LC3, microtubule-associated protein 1 light chain 3; shRNA, short hairpin RNA

Received 02.9.05; revised 20.2.06; accepted 13.3.06; Edited by G Kroemer; published online 28.4.06 
a

C

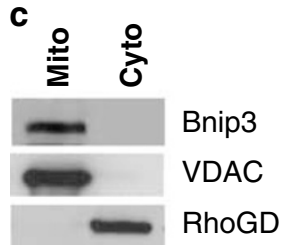

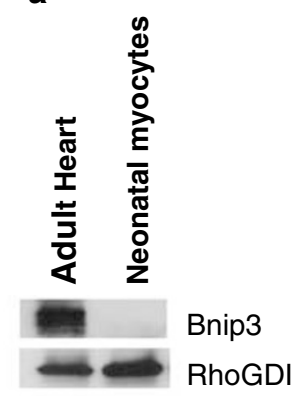

b

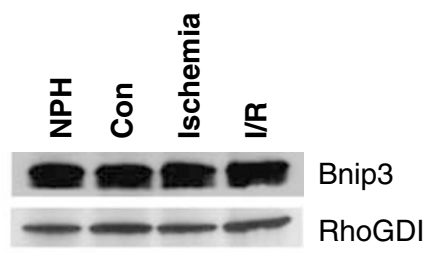

d Alkali:

$(-)(+)$

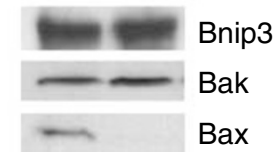

Figure 1 Expression of Bnip3 in adult myocardium. (a) Analysis of Bnip3 protein expression in whole-cell lysates from adult myocardium and in isolated neonatal cardiac myocytes. (b) Bnip3 protein levels in nonperfused rat hearts (NPH) and in hearts subjected to continuous perfusion (Con) or $30 \mathrm{~min}$ of global ischemia and $120 \mathrm{~min}$ of reperfusion (I/R) by Western blotting. (c) Subcellular fractionation of nonperfused heart lysates. (d) Alkali extraction of mitochondrial fraction

expression of Bnip3 in the adult myocardium, whereas Bnip3 was undetectable in neonatal cardiac myocytes under normal conditions (Figure 1a). Since Bnip3 has been reported to be induced by hypoxia in neonatal cardiac myocytes, ${ }^{8,10}$ we investigated whether Bnip3 expression increased in hearts subjected to $\mathrm{l} / \mathrm{R}$. We found no apparent change in the expression of Bnip3 protein after $30 \mathrm{~min}$ of ischemia and $120 \mathrm{~min}$ of reperfusion compared to control perfused hearts or freshly isolated nonperfused hearts (Figure 1b). Furthermore, subcellular fractionation experiments revealed that Bnip3 was exclusively associated with the mitochondria-enriched heavy membrane fraction (Figure 1c). The subcellular localization of Bnip3 did not change in the cells after $\mathrm{I} / \mathrm{R}$ (data not shown). To investigate whether Bnip3 is integrated into the mitochondrial membrane, we performed alkali extraction of proteins from mitochondria isolated from the heart. Bnip3 remained tightly associated with the mitochondrial membrane fraction following alkali treatment (Figure 1d). Bak and Bax were analyzed in parallel as controls. Bak, an integral mitochondrial membrane protein, was also resistant to treatment and remained associated with the membranes after alkaline incubation. In contrast, Bax was only loosely attached to mitochondria under normal conditions and most of Bax was lost during the treatment. These results indicate that Bnip3 exists as an integral mitochondrial membrane protein in the adult myocardium that is inactive in the absence of a death signal. The basis for Bnip3 inactivation is unknown at present.

Bnip3 in ischemia/reperfusion injury. We have established a technique of TAT protein transduction into isolated perfused hearts where linkage of the 11-amino-acid transduction domain of HIV TAT to a protein allows it to be readily transduced into cells in the heart. ${ }^{17,18}$ To determine whether Bnip3 plays a role in mediating I/R injury in the heart, we generated a TAT-fusion protein encoding the carboxyl terminal transmembrane deletion mutant of Bnip3 (TATBnip3 $\Delta T M$ ) which has been shown to act as a dominant negative to block Bnip3-induced cell death. ${ }^{8,10}$ Western blot analysis of heart lysates from hearts perfused with TATBnip3 $\triangle T M$ protein demonstrated that the TAT protein was readily taken up by the hearts after $15 \mathrm{~min}$ of perfusion (Figure 2a). Moreover, perfusion with TAT-Bnip3 $\Delta$ TM significantly reduced both creatine kinase (CK) release and infarct size in hearts subjected to $30 \mathrm{~min}$ of global ischemia and $120 \mathrm{~min}$ of reperfusion compared to TAT- $\beta$-gal (Figure $2 \mathrm{~b}$ and $\mathrm{c}$ ). We have previously demonstrated that TAT- $\beta$-gal has no effect on CK release and infarct size. ${ }^{17} \mathrm{I} / \mathrm{R}$ injury is associated with increased production of reactive oxygen species (ROS), such as superoxide anion, hydrogen peroxide, and hydroxyl radical. Bnip3 has been reported to increase ROS production when overexpressed in cells. ${ }^{11}$ To assess whether the cardioprotective effects of TATBnip3 $\triangle T M$ could be attributed to a reduction in the production of ROS, superoxide generation was measured in heart slices obtained after $30 \mathrm{~min}$ of ischemia and $15 \mathrm{~min}$ of reperfusion. Using dihydroethidium (DHE) staining to detect superoxide production, we found that TATBnip3 $\Delta T M$ attenuated superoxide production after $I / R$, suggesting that increased ROS production is partly due to activated Bnip3 in $\mathrm{I} / \mathrm{R}$ hearts (Figure 2d). Perfusion with TAT-Bnip3 $\Delta$ TM prior to ischemia also improved functional recovery after I/R compared with TAT- $\beta$-gal-perfused hearts (Figure $2 \mathrm{e}$ and $\mathrm{f}$ ).

Bnip3 and apoptosis. Overexpression of Bnip3 leads to loss of mitochondrial membrane potential and opening of the MPTP; both have been linked to the release of cytochrome $c$ from mitochondria. We found that hearts perfused with TAT-Bnip3 $\Delta$ TM exhibited reduced cytochrome $c$ and apoptosis-inducing factor (AIF) release after I/R compared to hearts perfused with TAT- $\beta$-gal (Figure 3a). Next, we investigated whether Bnip3 could directly induce release of proapoptotic factors from mitochondria. Addition of recombinant Bnip3 to purified heart mitochondria resulted in the release of cytochrome $c$ and AIF, whereas Bnip3 $\Delta$ TM had no effect (Figure $3 b$ ). Recombinant tBid, the proteolytically activated fragment of Bid, has previously been reported to induce the release of cytochrome $c$ from isolated mitochondria and was used as a positive control. ${ }^{19}$ Moreover, recombinant Bnip3 $\Delta$ TM directly inhibited Bnip3-mediated cytochrome $c$ and AIF release in vitro.

Next, we examined whether the protective effect of TATBnip3 $\Delta T M$ in $\mathrm{I} / \mathrm{R}$ was mediated by inhibition of apoptosis. Cardiac apoptosis was assessed in control perfused and in hearts perfused with TAT- $\beta$-gal or TAT-Bnip3 $\Delta$ TM prior to I/R by detection of cleaved (active) caspase-3 and terminal deoxynucleotideyltransferase-mediated dUTP nick end-labeling (TUNEL) of heart sections. Cells with activated caspase-3 were detected in hearts subjected to $\mathrm{I} / \mathrm{R}$ in the presence of TAT- $\beta$-gal, but not in hearts perfused with TAT-Bnip3 $\Delta$ TM 
a

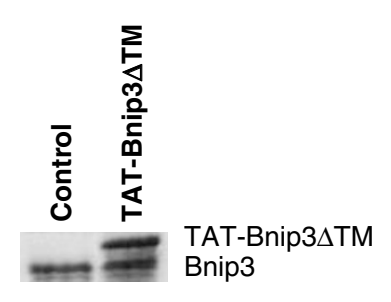

C
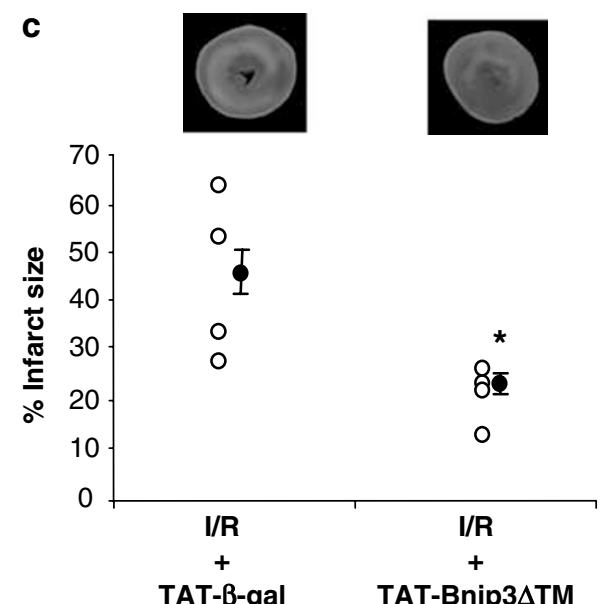

TAT- $\beta$-gal

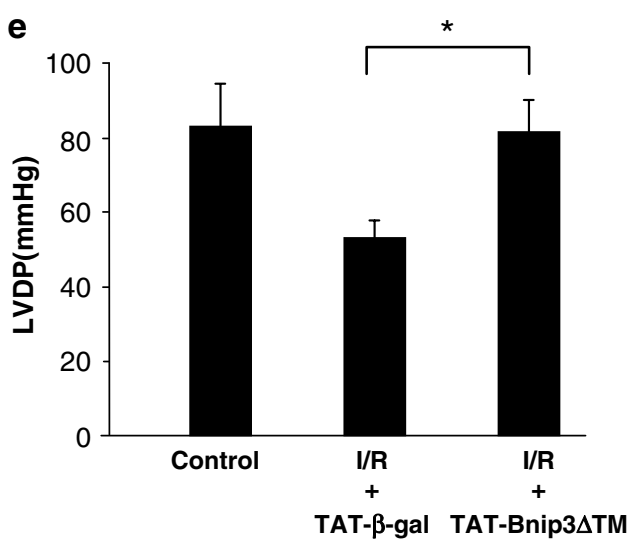

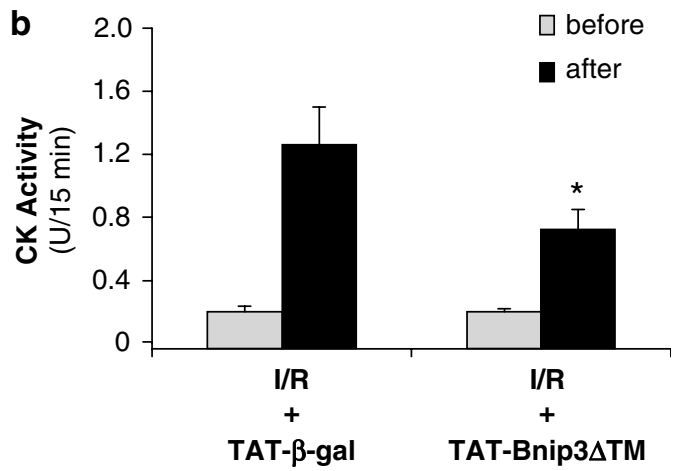

d
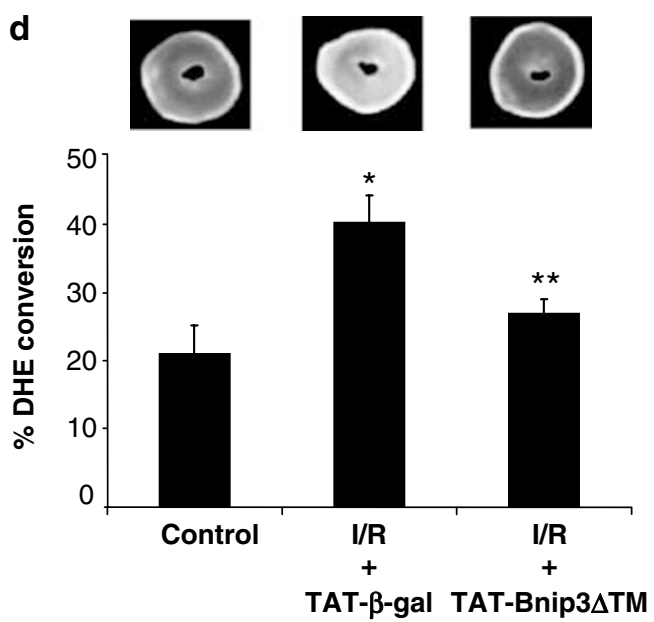

$\mathbf{f}$

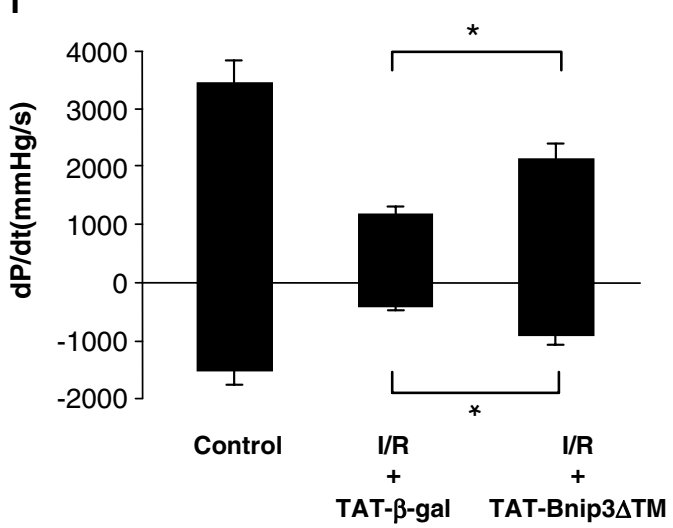

Figure 2 Effect of TAT-Bnip3 $\Delta$ TM transduction on I/R injury. Hearts were perfused with TAT-proteins for 15 min and then subjected to 30 min of global ischemia followed by reperfusion for $15 \mathrm{~min}$ (for superoxide production) or $120 \mathrm{~min}$ (for infarct size). (a) Western blot analysis of TAT-Bnip3 $\Delta$ TM protein transduction in hearts after $15 \mathrm{~min}$ of perfusion. (b) CK activity in the coronary effluent was measured for $15 \mathrm{~min}$ before ischemia and for the first 15 min of reperfusion $\left(n=8\right.$, $\left.{ }^{*} P<0.05\right)$. (c) Infarct size was determined by TTC staining $\left(n=4,{ }^{*} P<0.05\right)$. (d) Superoxide levels were assessed by measuring DHE conversion to ethidium $\left(n=4\right.$, $\left.{ }^{*} v e r s u s^{\star *}, P<0.05\right)$. Effect of TATBnip3 $\Delta T M$ on LVDP (e) and LV dP/dt (f) 60 min after ischemia/reperfusion. Data are mean \pm S.E.M. $\left({ }^{*} P<0.05, n=5\right)$

(Figure 4a). Moreover, TUNEL staining revealed that hearts perfused with TAT-Bnip3 $\Delta$ TM before I/R had significantly fewer apoptotic cells compared to TAT- $\beta$-gal perfused hearts (Figure $4 \mathrm{~b}-\mathrm{e}$ ). Taken together, these data suggest that Bnip3 plays a significant role in I/R-induced cell death by increasing ROS production, and releasing proapoptotic factors such as cytochrome $c$ and AIF which lead to activation of caspases and DNA fragmentation.
Bnip3 and HL-1 cardiac myocytes. To begin defining the molecular mechanism(s) by which Bnip3 mediates cell death during $\mathrm{I} / \mathrm{R}$, we turned to a cell culture model using the atrialderived cardiac myocyte cell line $\mathrm{HL}-1$. Overexpression of Bnip3 allowed us to mimic and monitor the effects of I/Rinduced Bnip3 activation in isolation from other molecular events occurring during I/R. To confirm that Bnip3 mediates the same effects in $\mathrm{HL}-1$ myocytes as in the intact heart, we 
a

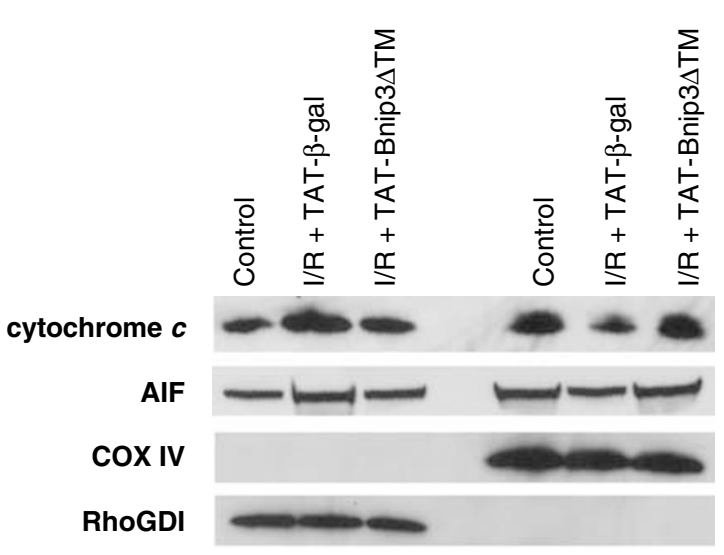

b

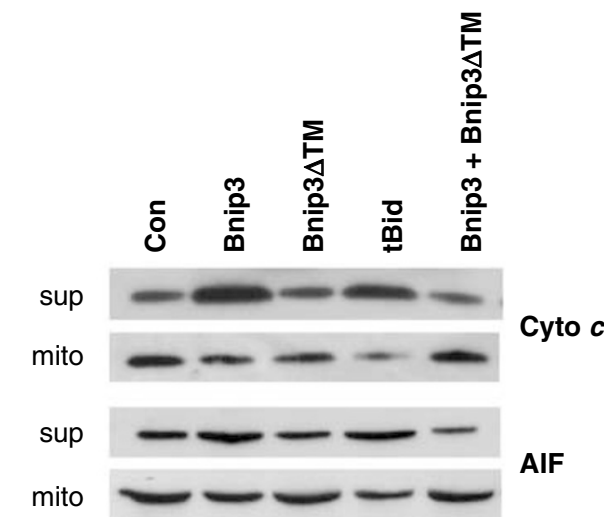

Figure 3 Effect of Bnip3 on cytochrome $c$ and AIF release. (a) Rat hearts perfused with TAT- $\beta$-gal or TAT-Bnip3 3 TM were subjected to $30 \mathrm{~min}$ of global ischemia followed by $15 \mathrm{~min}$ of reperfusion. Cytosol and mitochondrial fractions were analyzed by immunoblotting with antibodies to cytochrome $c$ (BD Biosciences), AIF (ProSci), COX-IV (Molecular Probes), and RhoGDI (Transduction Laboratories). Blot is representative of three replicate experiments. (b) Isolated heart mitochondria were incubated with recombinant Bnip3, Bnip3 $\Delta T M$, tBid, or Bnip3 plus Bnip3 $\Delta \mathrm{TM}$ for $60 \mathrm{~min}$ at $30^{\circ} \mathrm{C}$. Supernatants and pellets were analyzed by Western blotting for cytochrome $c$ and AIF release

overexpressed the dominant-negative Bnip3 $\Delta \mathrm{TM}$ prior to simulated $\mathrm{I} / \mathrm{R}$ (sl/R). We found that overexpression of Bnip3 $\Delta T M$ significantly reduced cell death after sl/R in $\mathrm{HL}$ 1 cardiac myocytes (Figure $5 a$ ). Similarly, downregulation of Bnip3 by RNA interference inhibited sl/R-mediated cell death, verifying that Bnip3 contributes to cell death in sl/R (Figure $5 b$ and c). Next, we investigated whether Bnip3mediated cell death in $\mathrm{sl} / \mathrm{R}$ was caused by activation of caspases. We found that cell death during $s \mathrm{l} / \mathrm{R}$ was significantly reduced in the presence of the broad spectrum caspase inhibitor, zVAD-fmk (Figure 5d). Furthermore, we found that overexpression of Bnip3 in HL-1 myocytes caused a significant increase in cell death which was inhibited in the presence of zVAD-fmk, suggesting that Bnip3-meditated cell death during $\mathrm{I} / \mathrm{R}$ is mediated through activation of caspases in HL-1 myocytes (Figure 5e). Nuclear condensation was characteristic of cell death mediated by both sl/R and Bnip3.
Bnip3 and autophagy. Upregulation of autophagy has been reported to occur in a rabbit model of $I / R$ and in chronically ischemic pig myocardium. ${ }^{20,21}$ Many studies have linked dysfunctional mitochondria with upregulation of autophagy. Thus, we speculated that Bnip3-induced mitochondrial damage in $\mathrm{I} / \mathrm{R}$ might upregulate autophagy in cardiac myocytes. Electron microscopy revealed the presence of autophagic vacuoles, recognized by their double-membrane vacuolar structures, ${ }^{22}$ in the myocardium following $\mathrm{I} / \mathrm{R}$, with many of the autophagosomes containing mitochondria (Figure 6A). Similarly, the presence of autophagosomes was detected by $\mathrm{EM}$ in $\mathrm{HL}-1$ cells after sl/R (Figure 6B). A characteristic of autophagy is the recruitment of the microtubule-associated protein 1 light chain 3 (LC3) to autophagic vesicles, which can be detected as punctate accumulations of GFP-LC3. ${ }^{23}$ Using GFP-LC3 as a specific marker autophagosome formation, we found that control cells transiently transfected with GFP-LC3 showed predominantly a diffuse distribution of green fluorescence, whereas $\mathrm{sl} / \mathrm{R}$ resulted in increased punctate patterns indicating enhanced formation of autophagosomes (Figure 6C). To investigate whether Bnip3 is involved in I/R-induced autophagy, we transfected HL-1 cells with the dominant-negative Bnip3 $\Delta$ TM along with GFP-LC3 before sl/R. We found that overexpression of Bnip3 $\Delta T M$ significantly reduced upregulation of autophagy in $\mathrm{HL}-1$ myocytes subjected to sl/R (Figure $6 \mathrm{D}$ ). To further investigate the link between I/R-induced autophagy and Bnip3 activation, HL-1 cells were transiently transfected with wild-type Bnip3 or Bnip3 $\triangle T M$ and the level of autophagy was assessed under normoxic conditions. As shown in Figure 7, overexpression of Bnip3 caused significant induction of autophagy compared to control cells. In contrast, Bnip3 $\Delta$ TM-transfected cells did not show a significant increase in autophagy (Figure $7 \mathrm{~b}$ ).

The autophagic response requires delivery of the contents sequestered by the autophagosome to the lysosome, whereupon degradation occurs. ${ }^{13}$ To verify that Bnip3-induced upregulation of autophagosomes reflected an increase in autophagic activity, and not a build-up of nonfused autophagosomes, we monitored the activity of the lysosomal compartments in Bnip3-transfected cells by staining cells with Lysotracker Red (LTR). We found colocalization of GFPLC3 and LTR, indicating fusion between the autophagosome and lysosome, hence functional autophagy (Figure 7c). We observed no differences in total LTR staining between control and Bnip3-overexpressing cells (data not shown). Also, we noted that the LTR staining was dispersed throughout the cell in acidic lysosomes in control cells, but was more concentrated to regions of high autophagosomal content in Bnip3overexpressing cells.

Autophagy and mitochondria. Several studies have reported that Bnip3 overexpression causes mitochondrial dysfunction. Since autophagy is an important process in removing damaged organelles, we investigated whether Bnip3-mediated mitochondrial damage caused upregulation of autophagy in HL-1 myocytes. Closer examination of mitochondria in Bnip3-overexpressing cells revealed extensive fragmentation of the mitochondrial network, whereas cells transfected with vector or Bnip3LTM had 
a

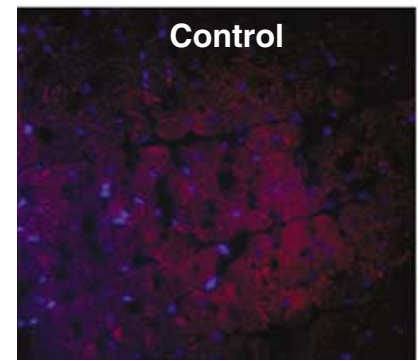

b
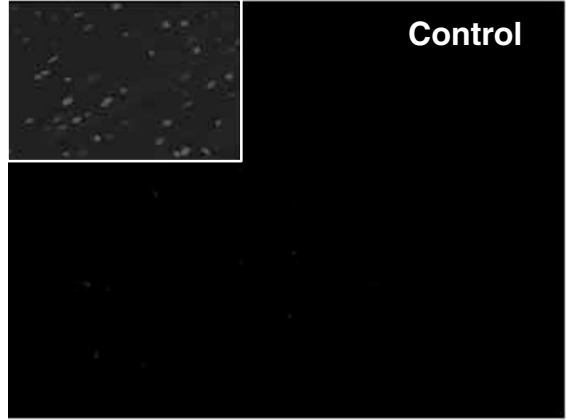

d

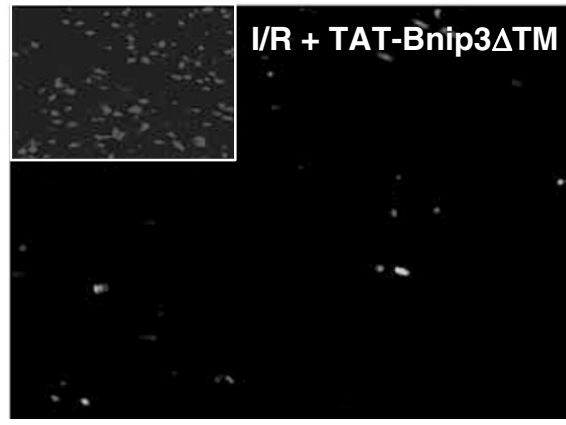

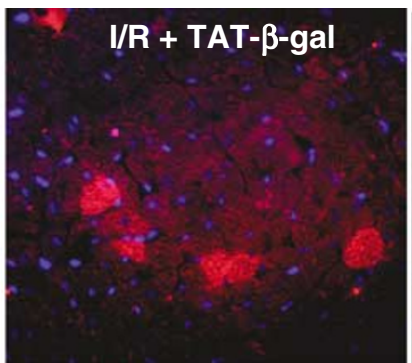

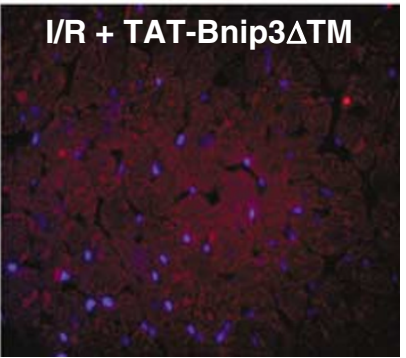

C
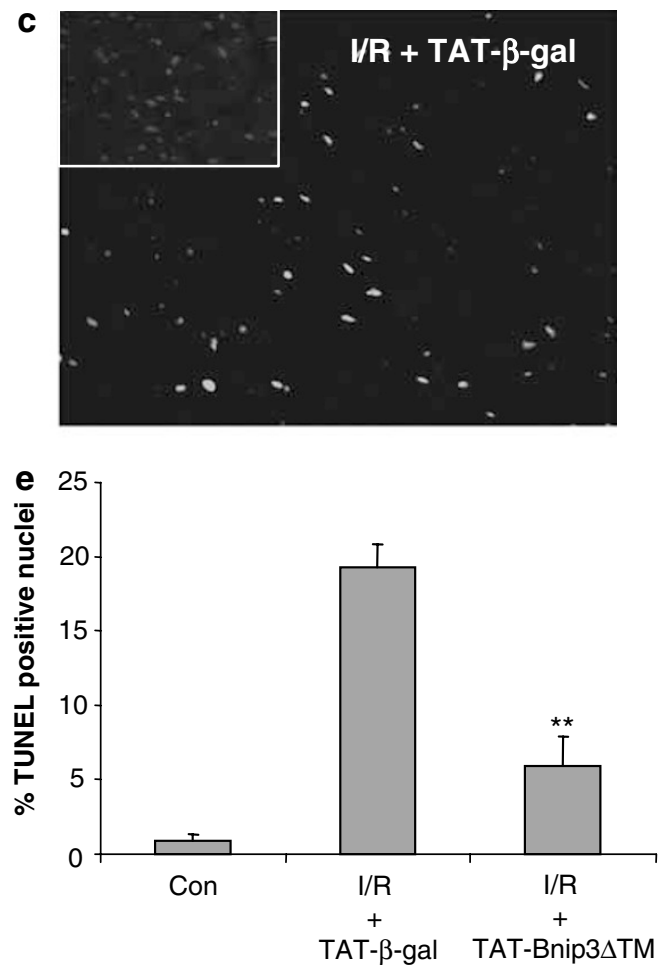

Figure 4 Effects of TAT-Bnip3 $\Delta$ TM transduction on ischemia and reperfusion (l/R)-induced caspase-3 cleavage and DNA fragmentation. Hearts were perfused with TATproteins for $15 \mathrm{~min}$ and then subjected to $30 \mathrm{~min}$ of ischemia and $120 \mathrm{~min}$ of reperfusion. (a) Immunofluorescent staining for cleaved caspase-3 (Red) and Hoechst 33342 (blue). (b-d) Representative photographs of TUNEL staining from three independent experiments. Nuclei were counterstained with Hoechst 33342 (inset). (e) TUNEL-positive nuclei were counted in 10 randomly selected fields of each condition and expressed as a percentage of the total number of nuclei (mean \pm S.D., $n=3$ ). I/R significantly increased TUNEL-stained nuclei compared with control hearts $\left({ }^{*} P<0.01\right.$ versus control). Treatment with TAT-Bnip3 $\Delta$ TM greatly decreased the occurrence of TUNEL-positive nuclei $\left({ }^{* *} P<0.01\right.$ versus $\mathrm{I} / \mathrm{R}+\mathrm{TAT}-\beta$-gal)

normal filamentous mitochondria (Figure 8). To examine whether these fragments of mitochondria were sequestered by autophagosomes (mitophagy), we employed laser scanning confocal microscopy of cells expressing mitoDsRed2 (to label mitochondria) and GFP-LC3 (to label autophagosomes). Analysis of generated Z-stacks revealed that extensive mitophagy occurred in Bnip3-cotransfected HL-1 cells, where many GFP-LC3-labeled autophagosomes colocalized with fragmented mitochondria (Figure 9a). 3D surface rendering of confocal Z-stacks revealed different stages of engulfment of individual mitochondria (Figure 9b). We did not observe instances of mitophagy in control or Bnip3 $\Delta$ TM-transfected cells (data not shown).

Recently, several studies have reported that autophagy may serve as a protective response. ${ }^{21,24,25}$ Thus, we hypothesized that upregulation of autophagy serves as a protective response against Bnip3-mediated injury likely by sequestering damaged mitochondria. ATG5 is a key molecule involved in autophagy and is essential for formation of autophagosomes. ${ }^{26}$ We found that overexpression of ATG5 significantly enhanced induction of autophagy in cells overexpressing Bnip3 compared to Bnip3 alone, and that this enhancement of autophagy correlated with reduction in Bnip3-mediated cell death (Figure 10a and b). In contrast, ATG5K130R, a dominant negative of ATG5 previously shown to suppress vacuole formation, ${ }^{27}$ significantly reduced autophagy and increased Bnip3-mediated cell death (Figure 10a and b). Similarly, overexpression of ATG5 enhanced autophagy during sl/R which correlated with reduced cell death, whereas ATGK130R reduced sl/R-induced autophagy while increasing cell death (data not shown). Thus, these data suggest that Bnip3-mediated mitochondrial dysfunction 
a

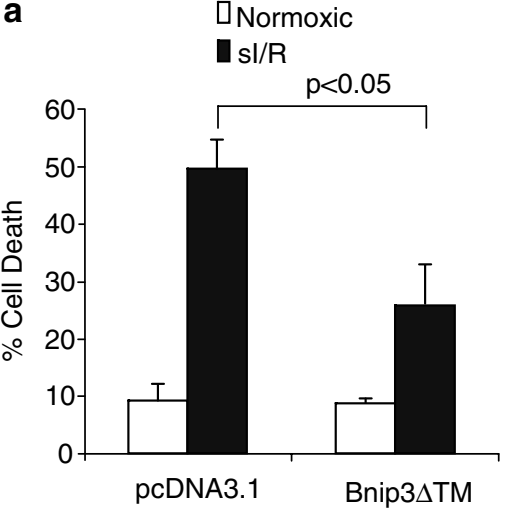

d

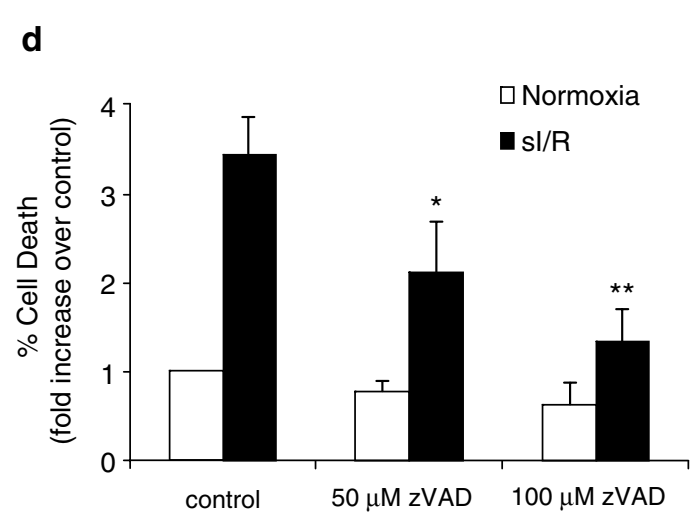

b

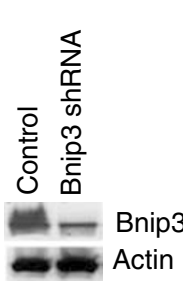

C

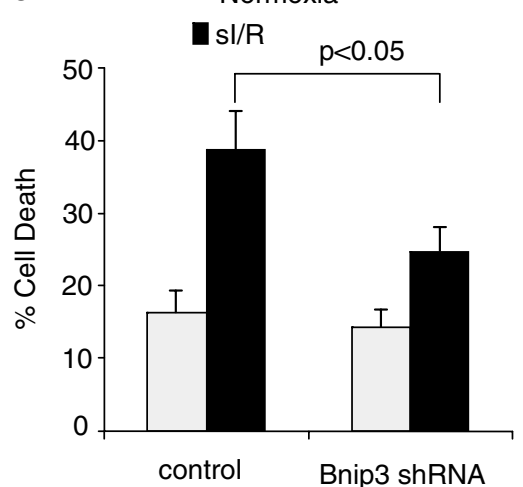

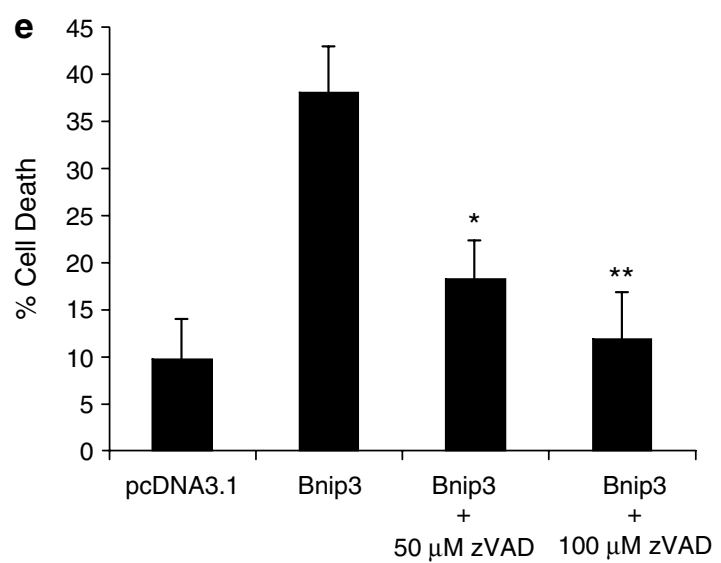

Figure 5 Role of caspases in I/R- and Bnip3-mediated cell death in $\mathrm{HL}-1$ myocytes. (a) Cells transiently transfected with vector or Bnip3 $3 \mathrm{TM}$ were subjected to $2 \mathrm{~h}$ of simulated ischemia and $12 \mathrm{~h}$ of reperfusion. Data are mean \pm S.E.M. of three independent experiments. (b) Western blot analysis of Bnip3 levels in HL-1 myocytes after $48 \mathrm{~h}$ transfection with control or Bnip3 interfering RNA (shRNA). (c) Cell death was determined after $2 \mathrm{~h}$ of simulated ischemia and $12 \mathrm{~h}$ of reperfusion in cells transfected with control or Bnip3 shRNA. Data are mean \pm S.E.M. of three independent experiments. (d) Cells were treated with DMSO or zVAD-fmk for 15 min prior to $2 \mathrm{~h}$ of simulated ischemia and $12 \mathrm{~h}$ of reperfusion (*** $\mathrm{P}<0.05$ versus sl/R). (e) $\mathrm{HL}-1$ myocytes transiently transfected with $\mathrm{pcDNA3} .1$ or Bnip3 were treated with zVAD-fmk and evaluated for dead cells $48 \mathrm{~h}$ post-transfection $\left(n=3,{ }^{*, *} P<0.05\right.$ versus Bnip 3$)$

during $\mathrm{I} / \mathrm{R}$ leads to upregulation of autophagy as a cellular stress response to dispose of damaged mitochondria.

\section{Discussion}

The Bcl-2 family members are important regulators of cell death in the myocardium. In the present study, we show that the mitochondrial protein Bnip3, a BH3-only member of the Bcl-2 family, contributes to I/R injury in the myocardium. We found that Bnip3 was expressed at substantial levels the adult myocardium, whereas Bnip3 was undetectable in neonatal cardiac myocytes. It is likely that Bnip3 exists in an inactive conformation in the absence of a death signal. Kubasiak et al. ${ }^{10}$ reported that hypoxia induced expression of Bnip3 in neonatal cardiac myocytes, but hypoxia alone did not signal apoptosis. For substantial apoptosis to occur, hypoxia had to be combined with acidosis, suggesting that Bnip3 activity is regulated by intracellular $\mathrm{pH}$. Several studies have reported that the development of intracellular acidosis plays an important role in apoptotic signaling. ${ }^{28,29}$ Ischemia is associated with a drop in intracellular $\mathrm{pH}$ from about 7.2 to $6.3^{30}$ which may be sufficient to activate Bnip3 in the mitochondria.
Bnip3 $\Delta T M$ has previously been reported to act as a dominant negative in Bnip3-mediated cell death. ${ }^{8,10}$ Accordingly, we examined whether Bnip3 $\Delta T M$ could reduce I/R injury in the myocardium. We found that perfusion of hearts with TAT-Bnip3 $\Delta$ TM protected against I/R injury as indicated by diminished $\mathrm{CK}$ release and infarct size, as well as improved cardiac function. Suppression of apoptosis by Bnip3 $\Delta T M$ was confirmed by TUNEL staining and immunostaining for active caspase-3. Since Bnip3 $\Delta \mathrm{TM}$ does not interact directly with full-length Bnip3, ${ }^{7}$ we hypothesize that it acts as a dominantnegative inhibitor of endogenous Bnip3 by competing for some regulatory factor required for Bnip3 activation. Further work will be necessary to establish the mechanism by which Bnip3 $\Delta$ TM protects against cell death.

The importance of mitochondria in determining cell viability after I/R has been increasingly recognized in the past few years. Mitochondrial dysfunction disrupts energy production and can trigger apoptosis. Since Bnip3 is localized exclusively to the mitochondria in myocardial cells and causes mitochondrial dysfunction when overexpressed, we speculated that Bnip3 might contribute to I/R injury through activation of the mitochondrial (intrinsic) pathway of apoptosis. Consistent with this, TAT-Bnip3 $\Delta$ TM was able to prevent cytochrome $c$ and 
A
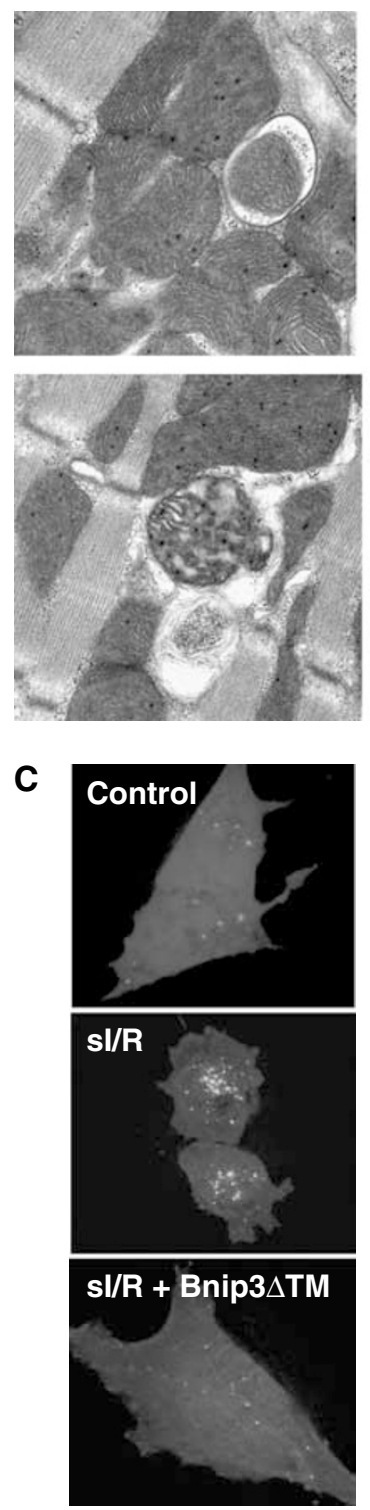

B
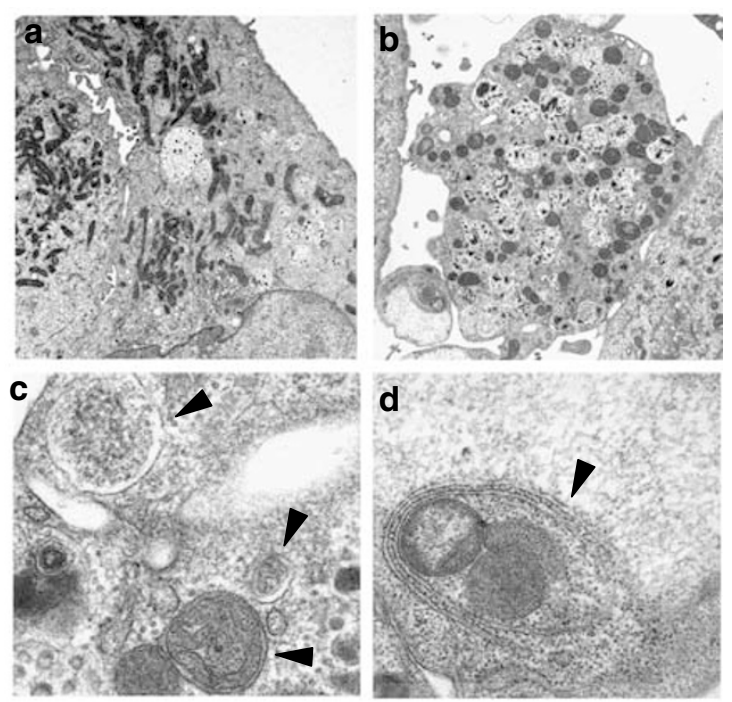

D

$\square$ Normoxic

$\mathrm{sl} / \mathrm{R}$

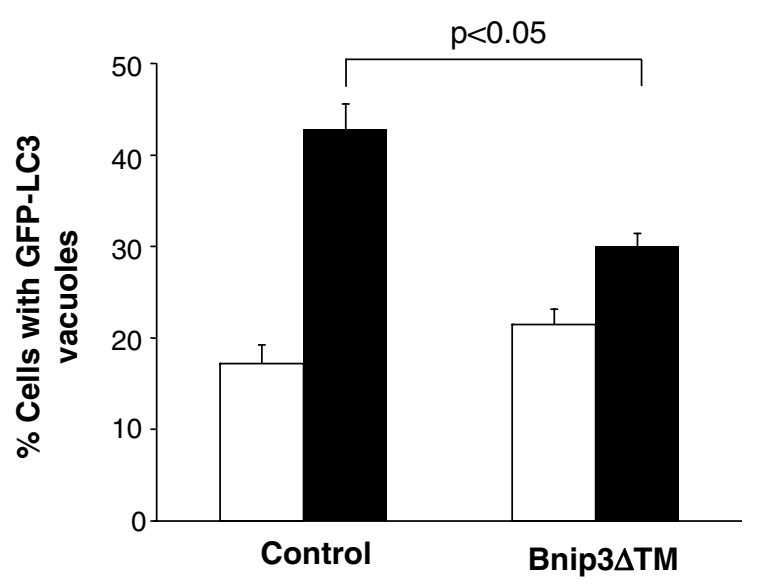

Figure 6 I/R leads to Bnip3-mediated upregulation of autophagy. (A) Electron micrographs of hearts subjected to I/R showing the presence of autophagosomes. (B) Electron micrographs of $\mathrm{HL}-1$ myocytes subjected to normoxia (a), or sI/R (b). Higher magnification of $\mathrm{HL}-1$ cells after sl/R (c and d). Arrowheads depict autophagosomes . (C) $\mathrm{HL}-1$ myocytes were transfected with GFP-LC3 and vector or Bnip3 $\Delta$ TM prior to sl/R. After $2 \mathrm{~h}$ of ischemia and $90 \mathrm{~min}$ of reperfusion, the extent of autophagy was assessed by analyzing staining patterns of GFP-LC3. (D) Quantitation of autophagy in HL-1 myocytes. Data are mean \pm S.E.M. of three independent experiments. Bnip3 $\Delta T M$ significantly reduced sl/R-induced autophagy in cells

AIF release in isolated perfused hearts subjected to $\mathrm{I} / \mathrm{R}$, and recombinant Bnip3 directly caused cytochrome $c$ and AIF release from mitochondria. Further investigation of the mechanism of Bnip3-mediated cell death revealed that caspases are involved in cell death induced by Bnip3 in $\mathrm{HL}-1$ cardiac myocytes. Similarly, Regula et al. ${ }^{8}$ reported that Bnip3-induced cell death was dependent on caspase activation. However, other studies have reported that overexpression of Bnip3 in cell lines did not induce detectable release of cytochrome $c$ from mitochondria and that Bnip3-mediated cell death occurred through a caspase-independent mechanism. ${ }^{10,11}$ This variation could be due to the differences in the systems used to study Bnip3 or it could reflect cell-specific regulation of Bnip3, including intracellular $\mathrm{pH}$.

In this study, we report that autophagy was present in the adult rat myocardium after $\mathrm{l} / \mathrm{R}$ and that many of the autophagosomes contained mitochondria. Upregulation of autophagy has been reported to serve as a protective response to various stressors including mitochondrial dysfunction. ${ }^{31,32}$ Recently, Yan et al. ${ }^{21}$ reported that chronic ischemia led to induction of autophagy in the myocardium. They found that areas in the myocardium with enhanced autophagy had fewer apoptotic cells, suggesting that induction of autophagy leads to inhibition of apoptosis. We have 
a
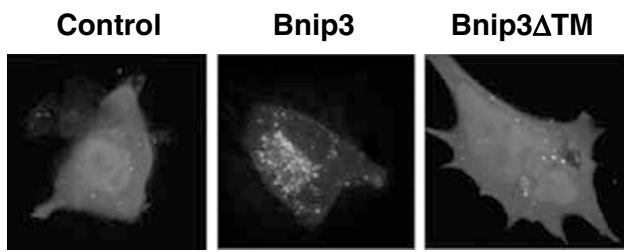

b

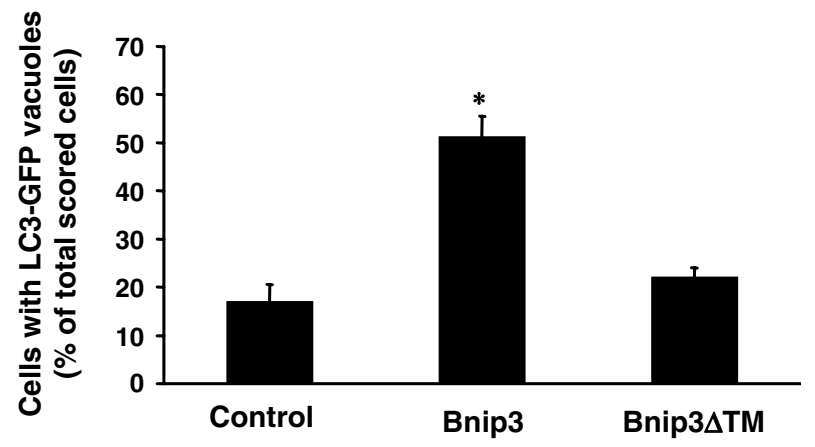

C

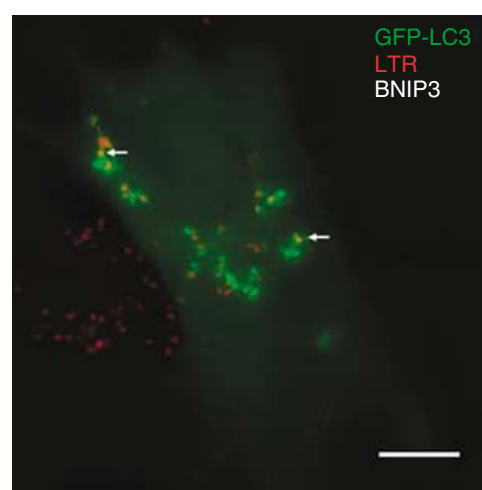

Figure 7 Overexpression of Bnip3 induces autophagy in $\mathrm{HL}-1$ cells. (a) $\mathrm{HL}-1$ myocytes were cotransfected with GFP-LC3 and pcDNA3.1, Bnip3, or Bnip3 $\Delta$ TM. After $48 \mathrm{~h}$, the extent of autophagy was assessed by analyzing staining patterns of GFP-LC3. (b) Quantitation of autophagy in transfected HL-1 myocytes. Overexpression of Bnip3 in cardiac myocytes significantly induced autophagy $\left({ }^{\star} P<0.05\right)$. The percentage of punctate GFP-LC3-positive cells per condition is shown as the mean \pm S.E.M. of three independent experiments. (c) Colocalization of LTR and GFP-LC3 demonstrate formation of autophagolysosomes. At $48 \mathrm{~h}$ following cotransfection with GFP-LC3 and Bnip3, HL-1 myocytes were loaded with $50 \mathrm{nM} \mathrm{LTR}$ for $5 \mathrm{~min}$ at RT. LTR staining was prominent in the area containing autophagosomes, and colocalized with GFP-LC3 labeled autophagosomes (arrows). Scale bar $=10 \mu \mathrm{m}$

linked Bnip3 to induction of autophagy in I/R. Moreover, we found that overexpression of Bnip3 resulted in extensive fragmentation of the mitochondria and a massive increase in autophagic vacuoles containing fragments of mitochondria in the absence of $\mathrm{I} / \mathrm{R}$. It is likely that the fragmented mitochondria may release proapoptotic factors such as cytochrome $c$ which can activate the intrinsic apoptotic pathway. Thus, upregulation of autophagy in response to Bnip3 activation may serve as a protective response by removing harmful and leaky mitochondria, thus preventing activation of apoptosis. Our data demonstrates that enhancing the autophagic process with ATG5 resulted in reduced cell death by Bnip3, whereas reducing autophagy with ATG5K130R produced the opposite
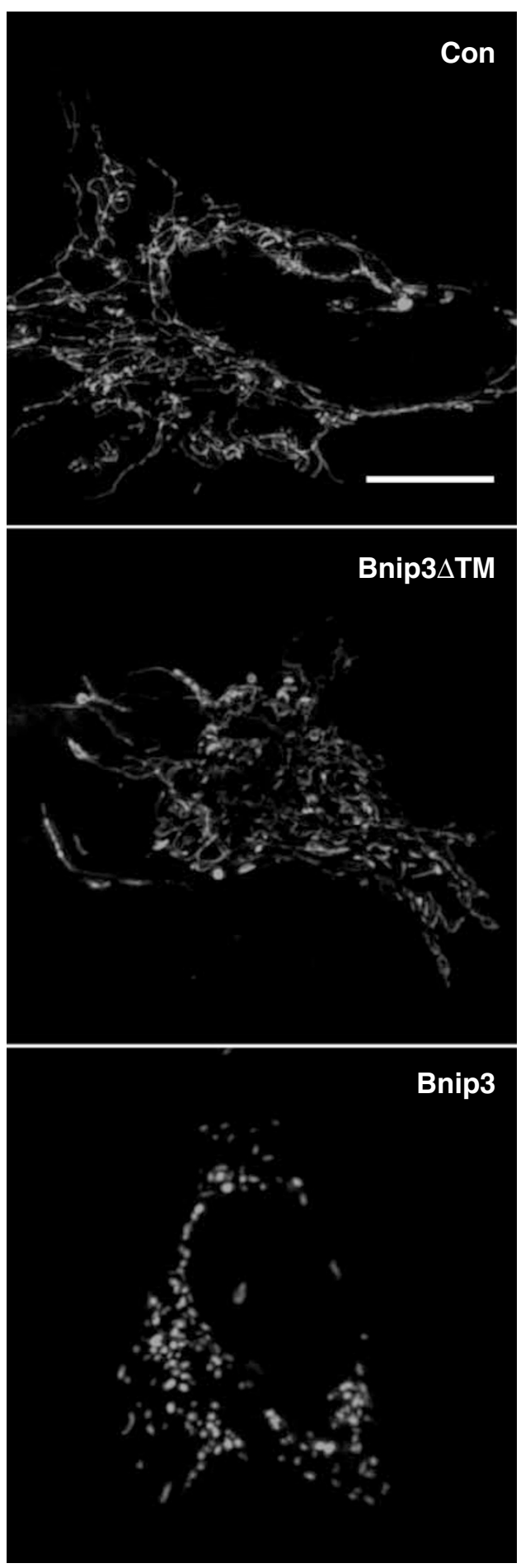

Figure 8 Bnip3 overexpression results in fragmentation of the mitochondrial network. Cells were cotransfected with mito-DsRed2 and pcDNA3.1, Bnip3, or Bnip3 $\Delta \mathrm{TM}$ and images were acquired $48 \mathrm{~h}$ after transfection. (Scale bar $=10 \mu \mathrm{m}$ )

effect. In fact, ATG5 overexpression protected against Bnip3mediated cell death even after $72 \mathrm{~h}$ of transfection (data not shown), suggesting that modulation of the autophagic pathway provides to protection over a prolonged period of time. However, although low levels of autophagy may constitute a 
a

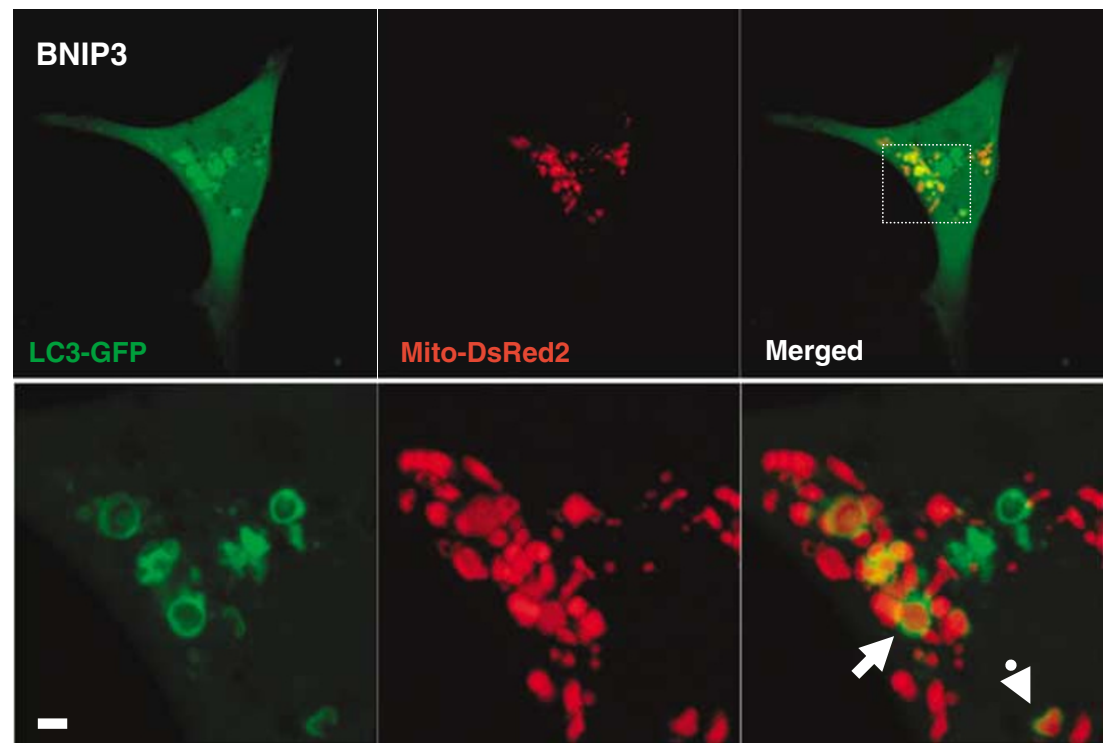

b

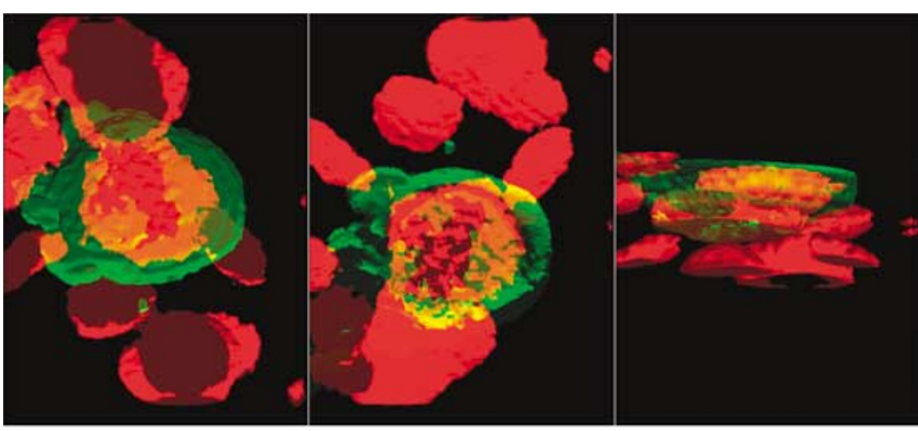

Sequestered

Mitochondrion

(i)

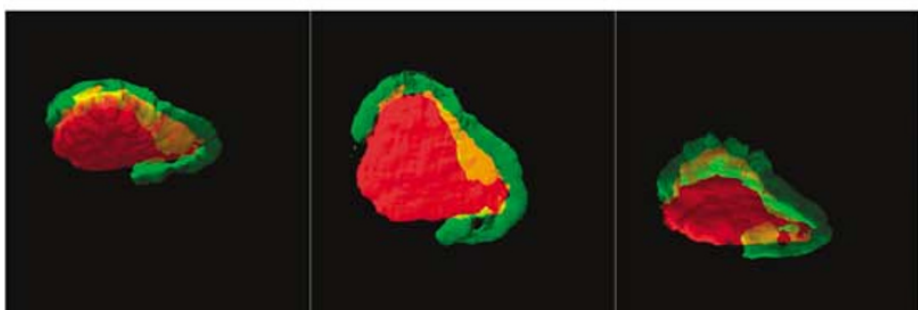

Figure 9 Bnip3 overexpression causes mitochondrial autophagy. HL-1 myocytes were cotransfected with mito-DsRed2, GFP-LC3 and Bnip3. At 48h following transfection, GFP-LC3 distribution and DsRed2-labeled mitochondria were detected by 3D confocal imaging (scale bar $=3 \mu \mathrm{m}$ ). (a) Mitochondria appeared fragmented and colocalized with autophagosomes. (b) Surface volume rendering of the structures denoted by arrows revealed mitochondrial autophagy in 3D showing different stages of mitochondrial engulfment in Bnip3-overexpressing cells. (i) Engulfed mitochondrion (b, closed arrow) and (ii) mitochondrion undergoing sequestration (b, open arrow)

protective mechanism by removal of damaged mitochondria, excessive autophagy may lead to cell death. Presently, it is unknown what triggers damaged mitochondria to be removed by autophagy.

It is not known whether Bnip3 directly induces autophagy or whether autophagy is induced as a consequence of mitochondrial damage caused by Bnip3. Several studies have reported that overexpression of Bnip3 induces cell death

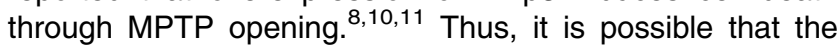
MPTP serves as an upstream signal for mitochondrial autophagy in I/R. Similary, Elmore et al. ${ }^{31}$ reported that opening of the MPTP triggered autophagy of damaged mitochondria in hepatocytes. The MPTP has also been reported to play a role in $\mathrm{I} / \mathrm{R}$ injury. Recent studies have reported that preventing MPTP opening protects against I/R injury. ${ }^{33,34}$ Moreover, mice lacking cyclophilin $D$, a component of the MPTP, are more resistant to I/R injury, whereas transgenic mice overexpressing cyclophilin D exhibited swollen mitochondria and increased spontaneous cell death. $^{35}$ This suggests that Bnip3-mediated mitochondrial damage through opening of the MPTP may be the cause of enhanced autophagy.

In this report, we demonstrate that Bnip3 contributes to I/R injury in the heart. Bnip3 causes disruption of mitochondrial integrity, leading to enhanced superoxide production and the release of proapoptotic factors, such as cytochrome $c$ and 

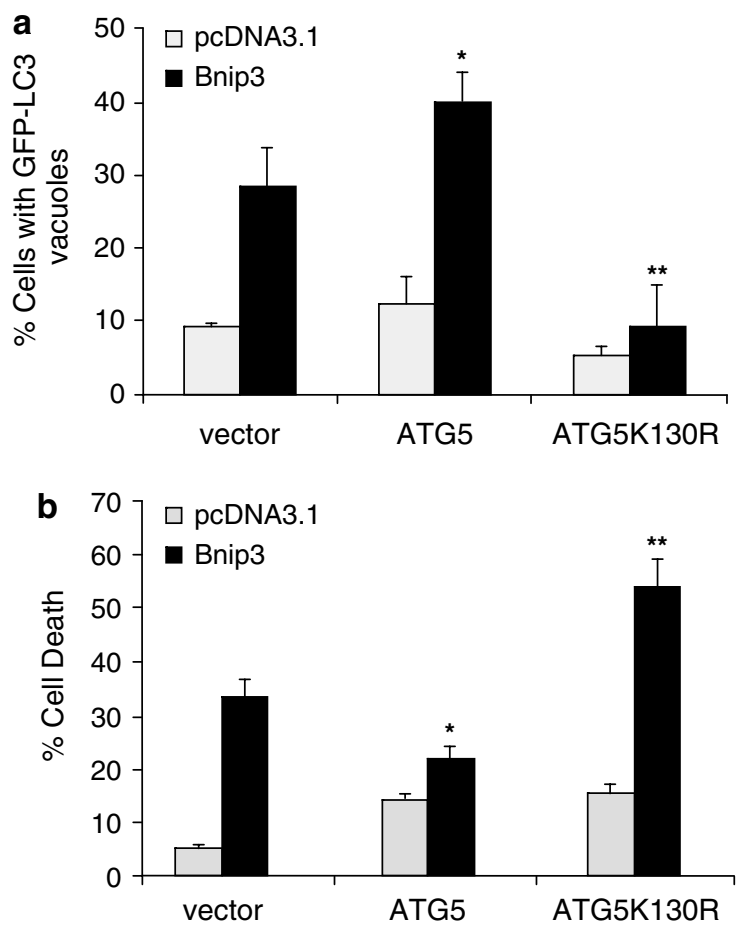

Figure 10 Modulation of autophagy affects Bnip3-mediated cell death. (a) HL-1 myocytes were cotransfected with vector, ATG5 or ATG5K130R, and pcDNA3.1 or Bnip3 and GFP-LC3 to monitor formation of autophagosomes as described in Materials and Methods. (b) Cells were transfected with pcDNA3.1 or Bnip3 and vector, ATG5 or ATG5K130R and cell death was assessed $48 \mathrm{~h}$ after transfection as described in Materials and Methods. Data are mean \pm S.E.M. $\left(n=3,{ }^{*, \star *} P<0.05\right)$

AIF. Moreover, we show that $\mathrm{I} / \mathrm{R}$ induces autophagy in a Bnip3-dependent manner. Taken together, these findings implicate Bnip3 as a major contributor to myocardial injury by causing mitochondrial dysfunction, which is associated with upregulation of autophagy as a protective cellular stress response.

\section{Materials and Methods}

Recombinant protein expression and purification. TAT- $\beta$-gal and TAT-Bnip3 $\Delta$ TM fusion proteins were purified as previously described. ${ }^{17}$ His-tagged Bnip3 and Bnip3 $\Delta$ TM were grown in BL21(DE3) cells (Invitrogen) and expression was induced with $1 \mathrm{mM} I P T G$ for $4 \mathrm{~h}$. The bacteria were resuspended in Native buffer $\left(150 \mathrm{~mm} \mathrm{NaCl}, 1 \%\right.$ Tween-20, $50 \mathrm{mM} \mathrm{NaH}_{2} \mathrm{PO}_{4}, \mathrm{pH} 8.0$, and complete protease inhibitors (Roche)), followed by sonication on ice. After centrifugation at $20000 \times g$ for $20 \mathrm{~min}$, the supernatants were added to columns containing Ni-NTA (Qiagen Inc.). The proteins were eluted with $250 \mathrm{~mm}$ imidazole in Native buffer, followed by desalting on PD-10 columns (Amersham-Pharmacia).

Isolation of neonatal cardiac myocytes. Neonatal rat cardiac myocytes were prepared by collagenase digestion as previously described ${ }^{28}$ Cells were plated on gelatin-coated dishes for $24 \mathrm{~h}$.

Langendorff perfusion and ischemia/reperfusion. Hearts from anesthetized male Sprague-Dawley rats $(225-250 \mathrm{~g})$ were rapidly excised and cannulated onto the Langendorff perfusion apparatus using a protocol adapted from Tsuchida et $a l .{ }^{36}$ The hearts were perfused with or without $50 \mathrm{nM}$ TAT protein and subjected to I/R as described. ${ }^{17}$ The Creatine Kinase (CK) activity in the coronary effluent was measured using a diagnostic kit (Stanbio Laboratory) and infarct size was measured using triphenyl tetrazolium staining. Superoxide production was assessed via the conversion of DHE to ethidium as described. ${ }^{37}$ For hemodynamic measurements, a thin plastic balloon filled with water was inserted into the left ventricle and connected to a pressure transducer (EMKA Technologies).

Immunohistochemistry. After perfusion, hearts were fixed with $4 \%$ formaldehyde, embedded, and thin-sectioned, followed by deparaffinization and rehydration. Sections were blocked in $5 \%$ goat serum and then incubated overnight at $4{ }^{\circ} \mathrm{C}$ with an antibody against cleaved caspase-3 (Cell Signaling Technology). Nonspecific staining was assessed by omitting the primary antibody. After washing, sections were incubated for $2 \mathrm{~h}$ at room temperature with anti-mouse Alexa 594 (Molecular Probes). In situ labeling of fragmented DNA in heart sections was performed using the In Situ Cell Death Detection kit (Roche Applied Science) according to the manufacturer's instructions. Nuclei were counterstained with Hoechst 33342 (Molecular Probes).

Preparation of mitochondria and cytosol and Western blotting. The isolation of mitochondria and cytosol and Western blotting were carried out as previously described. ${ }^{18}$ Briefly, ventricles were minced and homogenized by polytron in ice-cold MSE buffer $(220 \mathrm{~mm}$ mannitol, $70 \mathrm{mM}$ sucrose, $2 \mathrm{mM}$ EGTA, $5 \mathrm{mM}$ MOPS pH 7.4, and $0.2 \% \mathrm{BSA}$ ). The lysates were centrifuged for $10 \mathrm{~min}$ at $600 \times g$ to remove unbroken tissue and nuclei, and the supernatants were centrifuged for $10 \mathrm{~min}$ at $3000 \times g$ to pellet mitochondria. The supernatant was centrifuged for $30 \mathrm{~min}$ at $100000 \times g$ to obtain cytosol, while the mitochondrial fraction was resuspended in Incubation Buffer containing $180 \mathrm{~mm}$ mannitol, $70 \mathrm{~mm}$ sucrose, $10 \mathrm{~mm} \mathrm{KCl}, 10 \mathrm{~mm} \mathrm{MgCl}$, $1 \mathrm{~mm}$ EGTA, $5 \mathrm{~mm} \mathrm{KH}_{2} \mathrm{PO}_{4}$, and $10 \mathrm{mM}$ MOPS $\mathrm{pH} 7.4$.

Alkali extraction. Freshly isolated heart mitochondria were resuspended in freshly prepared $0.1 \mathrm{M} \mathrm{Na}_{2} \mathrm{CO}_{3}(\mathrm{pH} 11.5)$ and incubated for $20 \mathrm{~min}$ on ice. The membranes were recovered by centrifugation at $100000 \times g$ for $30 \mathrm{~min}$, separated by SDS-PAGE, and analyzed by immunoblotting using an antibody against Bnip3 (Sigma), Bak (G-23, Santa Cruz), or Bax (N-20, Santa Cruz).

Assessment of cytochrome $c$ and AIF release. Heart mitochondria $(50 \mu \mathrm{g})$ were incubated with vehicle, Bnip3 $(1 \mu \mathrm{g})$, Bnip3 $\Delta \mathrm{TM}(1 \mu \mathrm{g})$, or tBid $(100 \mathrm{ng})$ for $60 \mathrm{~min}$ at $30^{\circ} \mathrm{C}$, and cytochrome $c$ and AIF release was determined by Western blotting as described. ${ }^{18}$

Electron microscopy. Hearts were perfused with $4 \%$ paraformaldehyde, $1.5 \%$ glutaraldehyde in $0.1 \mathrm{M} \mathrm{Na}$ cacodylate buffer, postfixed in $1 \%$ osmium tetroxide, dehydrated in ethanol, treated in propylene oxide and embedded in EMbed 812/Araldite (Electron Microscopy Sciences, Fort, Washington, PA, USA). HL-1 myocytes were fixed in $2.5 \%$ glutaraldehyde in $0.1 \mathrm{M}$ cacodylate buffer, postfixed in $1 \%$ osmium tetroxide, and then treated with $0.5 \%$ tannic acid, $1 \%$ sodium sulfate, cleared in 2-hydroxypropyl methacrylate and embedded in LX112 (Ladd Research, Williston, VT, USA). Sections were mounted on copper slot grids coated with parlodion and stained with uranyl acetate and lead citrate for examination on a Philips CM100 electron microscope (FEI, Hillsbrough, OR, USA).

Cell culture model of ischemia/reperfusion. Atrial derived $\mathrm{HL}-1$ mouse cardiac myocytes ${ }^{38}$ were cultured in Claycomb medium (JRH Biosciences) supplemented with $10 \%$ fetal bovine serum, $0.1 \mathrm{mM}$ norepinephrine, $2 \mathrm{mM} \mathrm{L}$ glutamine, $100 \mathrm{U} / \mathrm{ml}$ penicillin, $100 \mathrm{U} / \mathrm{ml}$ streptomycin, and $0.25 \mu \mathrm{g} / \mathrm{ml}$ amphotericin B. Simulated ischemia was introduced by incubating cells in ischemic buffer $\left(125 \mathrm{~mm} \mathrm{NaCl}, 8 \mathrm{~mm} \mathrm{KCl}, 1.2 \mathrm{mM} \mathrm{KH}_{2} \mathrm{PO}_{4}, 1.25 \mathrm{mM} \mathrm{MgSO}_{4}, 1.2 \mathrm{mM} \mathrm{CaCl}_{2}, 6.25 \mathrm{~mm}\right.$ $\mathrm{NaHCO}_{3}, 20 \mathrm{~mm}$ 2-deoxyglucose, $5 \mathrm{~mm}$ Na-lactate, $20 \mathrm{~mm}$ HEPES, pH 6.6) and placing the dishes in hypoxic pouches (GasPak ${ }^{\mathrm{TM}} \mathrm{EZ}, \mathrm{BD}$ Biosciences) for $2 \mathrm{~h}$ at $37^{\circ} \mathrm{C}$. Reperfusion was initiated by changing to Krebs-Henseleit buffer $(110 \mathrm{~mm}$ $\mathrm{NaCl}, 4.7 \mathrm{mM} \mathrm{KCl}, 1.2 \mathrm{mM} \mathrm{KH}_{2} \mathrm{PO}_{4}, 1.25 \mathrm{mM} \mathrm{MgSO}_{4}, 1.2 \mathrm{mM} \mathrm{CaCl}_{2}, 25 \mathrm{mM}$ $\mathrm{NaHCO}_{3}, 15 \mathrm{~mm}$ glucose, $20 \mathrm{~mm}$ HEPES, pH 7.4).

Short hairpin RNA and cell death. Sequences with 100\% homology to mouse Bnip3 were generated using BLOCK- $\mathrm{T}^{\mathrm{TM}}$ RNAi Designer (Invitrogen). The target sequence TCCAGCCTCCGTCTCTATTTA (78-98) showed no significant homology to other mouse proteins as determined by BLAST analysis. The sequence was used to generate oligonucleotide pairs, and inserted into the pcDNA6.2-GW/EmGFP-miR vector. To control for nonspecific RNAi effects, the construct pcDNA6.2-GW/EmGFP-miR-LacZ was used as a control. The short 
hairpin RNA plasmids were introduced into cells by transient transfections using Effectene (QIAGEN) according to manufacturer's instructions with a transfection efficiency of $75-90 \%$. Bnip3 protein levels were typically reduced $80-90 \%$ after $48 \mathrm{~h}$ of transfections. After $48 \mathrm{~h}$ of transfection, the cells were subjected to $2 \mathrm{~h}$ of simulated ischemia and $12 \mathrm{~h}$ of reperfusion. Cells were stained with Hoechst 33342 to assess nuclear morphology of GFP-positive cells.

DNA constructs. EGFP of the vector pEGFP-C1 (Clonetech) was replaced with mCherry, ${ }^{39}$ generating the pmCherry-C1 vector. ATG5 was amplified from mouse CDNA by PCR and ligated into pmCherry-C1 vector. The K130R mutation was generated using site-directed mutagenesis as previously described. ${ }^{27}$

Quantitation of cell death and autophagy. HL-1 cardiac myocytes were transfected with GFP-LC3 and either pcDNA3.1, Bnip3, or Bnip3 $\Delta$ TM using Effectene according to the manufacturer's instruction (Qiagen). The transfection efficiency of $\mathrm{HL}-1$ cells was around $40 \%$. To determine cell death, $\mathrm{HL}-1$ cells were cotransfected with pDsRed2 and pcDNA3.1 or Bnip3 $\Delta \mathrm{TM}$. pDsRed2-positive cells were evaluated for cell death $48 \mathrm{~h}$ after transfection or $12 \mathrm{~h}$ after reperfusion using YoPro1 (Molecular Probes) fluorescence staining as previously described. ${ }^{40}$ YoPro1 is a nuclear dye that only stains permeable cells undergoing apoptosis and is completely excluded from healthy living cells. To quantify autophagy, fixed cells were classified as cells with predominantly diffuse GFP-LC3 fluorescence or punctate GFP-LC3 pattern $48 \mathrm{~h}$ after transfection. Cells were observed through a Nikon TE300 fluorescence microscope (Nikon) equipped with a cooled CCD camera (Orca-ER, Hamamatsu). At least $75-150$ cells were scored from two replicate dishes in three independent experiments.

Laser scanning confocal microscopy (LSCM). LSCM was performed with a Bio-Rad Radiance 2100 laser scanning confocal microscope (Hercules, CA USA) using a $\times 60$ Plan Apo objective (1.4 N.A oil immersion lens; Nikon, Japan), equipped with both a mixed gas Helium-Neon $(543 \mathrm{~nm})$ laser and an Argon $(488 \mathrm{~nm})$ laser, and operated through Bio-Rad LaserSharp 2000 software. Green and red fluorescence were directed to separate photomultipliers by a $560-\mathrm{nm}$ longpass dichroic reflector through HQ530SP and HQ590/70 emission filters, respectively. The confocal pinholes were configured so as to obtain images of $0.7 \mu \mathrm{m}$ in the axial dimension and step increments were $0.3 \mu \mathrm{m}$.

\section{Acknowledgements}

HL-1 cells were kindly provided by Dr. Claycomb (LSU Health Sciences Center, Louisiana). We are grateful for the the GFP-LC3 from Dr. T Yoshimori (National Institute of Genetics, Japan), and the pRSET-mCherry from Dr. R Tsien (University of California, San Diego, USA). We appreciate the help of Dr Malcolm Wood (The Scripps Research Institute) with the electron microscopy experiments. This research was supported by $\mathrm{NIH} \mathrm{R01-HL60590} \mathrm{(to} \mathrm{RAG),} \mathrm{an} \mathrm{American} \mathrm{Heart}$ Association, Western Regional Affiliate postdoctoral fellowship and by funds from the California Tobacco-Related Disease Research Program of the University of California, Grant Number 14KT-0109 (to ÅBG), and the Stein endowment fund. This is MS\# 17321-MEM of The Scripps Research Institute.

1. Searle J, Kerr JF, Bishop CJ. Necrosis and apoptosis: distinct modes of cell death with fundamentally different significance. Pathol Annu 1982; 17 (Part 2): 229-259.

2. Olivetti G, Quaini F, Sala R, Lagrasta C, Corradi D, Bonacina E et al. Acute myocardial infarction in humans is associated with activation of programmed myocyte cell death in the surviving portion of the heart. J Mol Cell Cardiol 1996; 28: 2005-2016.

3. Narula J, Haider N, Virmani R, DiSalvo TG, Kolodgie FD, Hajiar RJ et al. Apoptosis in myocytes in end-stage heart failure. N Engl J Med 1996; 335: 1182-1189.

4. Wang K, Yin XM, Chao DT, Milliman CL, Korsmeyer SJ. BID: a novel BH3 domain-only death agonist. Genes Dev 1996; 10: 2859-2869.

5. Yasuda M, Theodorakis $P$, Subramanian T, Chinnadurai G. Adenovirus E1B-19K/BCL-2 interacting protein $\mathrm{BNIP} 3$ contains a $\mathrm{BH} 3$ domain and a mitochondrial targeting sequence. J Biol Chem 1998; 273: 12415-12421.

6. Ray R, Chen G, Vande VC, Cizeau J, Park JH, Reed JC et al. BNIP3 heterodimerizes with $\mathrm{Bcl}-2 / \mathrm{Bcl}-\mathrm{X}(\mathrm{L})$ and induces cell death independent of a Bcl-2 homology $3(\mathrm{BH} 3)$ domain at both mitochondrial and nonmitochondrial sites. J Biol Chem 2000; 275: 1439-1448.

7. Chen G, Ray R, Dubik D, Shi L, Cizeau J, Bleackley RC et al. The E1B 19K/Bcl-2-binding protein Nip3 is a dimeric mitochondrial protein that activates apoptosis. J Exp Med 1997; 186: $1975-1983$.
8. Regula KM, Ens K, Kirshenbaum LA. Inducible expression of BNIP3 provokes mitochondrial defects and hypoxia-mediated cell death of ventricular myocytes. Circ Res 2002; 91: 226-231.

9. Bruick RK. Expression of the gene encoding the proapoptotic Nip3 protein is induced by hypoxia. Proc Natl Acad Sci USA 2000; 97: 9082-9087.

10. Kubasiak LA, Hernandez OM, Bishopric NH, Webster KA. Hypoxia and acidosis activate cardiac myocyte death through the Bcl-2 family protein BNIP3. Proc Natl Acad Sci USA 2002; 99: 12825-12830.

11. Vande VC, Cizeau J, Dubik D, Alimonti J, Brown T, Israels S et al. BNIP3 and genetic control of necrosis-like cell death through the mitochondrial permeability transition pore. Mol Cell Biol 2000; 20: 5454-5468.

12. Daido S, Kanzawa T, Yamamoto A, Takeuchi H, Kondo Y, Kondo S. Pivotal role of the cell death factor BNIP3 in ceramide-induced autophagic cell death in malignant glioma cells. Cancer Res 2004; 64: 4286-4293.

13. Levine B. Eating oneself and uninvited guests: autophagy-related pathways in cellular defense. Cell 2005; 120: 159-162.

14. Liang XH, Jackson S, Seaman M, Brown K, Kempkes B, Hibshoosh $\mathrm{H}$ et al. Induction of autophagy and inhibition of tumorigenesis by beclin 1. Nature 1999; 402: 672-676.

15. Shimomura H, Terasaki $F$, Hayashi $T$, Kitaura $Y$, Isomura $T$, Suma $H$. Autophagic degeneration as a possible mechanism of myocardial cell death in dilated cardiomyopathy. Jpn Circ J 2001; 65: 965-968.

16. Yuan J, Lipinski M, Degterev A. Diversity in the mechanisms of neuronal cell death. Neuron 2003; 40: 401-413

17. Gustafsson AB, Sayen MR, Williams SD, Crow MT, Gottlieb RA. TAT protein transduction into isolated perfused hearts: TAT-apoptosis repressor with caspase recruitment domain is cardioprotective. Circulation 2002; 106: 735-739

18. Gustafsson AB, Tsai JG, Logue SE, Crow MT, Gottlieb RA. Apoptosis repressor with caspase recruitment domain protects against cell death by interfering with Bax activation. $J$ Biol Chem 2004; 279: 21233-21238.

19. Chen M, He H, Zhan S, Krajewski S, Reed JC, Gottlieb RA. Bid is cleaved by calpain to an active fragment in vitro and during myocardial ischemia/reperfusion. J Biol Chem 2001; 276: 30724-30728.

20. Decker RS, Poole AR, Crie JS, Dingle JT, Wildenthal K. Lysosomal alterations in hypoxic and reoxygenated hearts. II. Immunohistochemical and biochemical changes in cathepsin D. Am J Pathol 1980; 98: 445-456.

21. Yan L, Vatner DE, Kim SJ, Ge H, Masurekar M, Massover WH et al. Autophagy in chronically ischemic myocardium. Proc Natl Acad Sci USA 2005; 102: 13807-13812.

22. Dunn Jr WA. Studies on the mechanisms of autophagy: formation of the autophagic vacuole. J Cell Biol 1990; 110: 1923-1933.

23. Kabeya Y, Mizushima N, Ueno T, Yamamoto A, Kirisako T, Noda T et al. LC3, a mammalian homologue of yeast Apg8p, is localized in autophagosome membranes after processing. EMBO J 2000; 19: 5720-5728.

24. Boya P, Gonzalez-Polo RA, Casares N, Perfettini JL, Dessen P, Larochette N et al. Inhibition of macroautophagy triggers apoptosis. Mol Cell Biol 2005; 25: $1025-1040$

25. Lum JJ, Bauer DE, Kong M, Harris MH, Li C, Lindsten T et al. Growth factor regulation of autophagy and cell survival in the absence of apoptosis. Cell 2005; 120 : 237-248.

26. Mizushima N, Yamamoto A, Hatano M, Kobayashi Y, Kabeya Y, Suzuki K et al. Dissection of autophagosome formation using Apg5-deficient mouse embryonic stem cells. J Cell Biol 2001; 152: 657-668

27. Pyo JO, Jang MH, Kwon YK, Lee HJ, Jun Jl, Woo HN et al. Essential roles of Atg5 and FADD in autophagic cell death: dissection of autophagic cell death into vacuole formation and cell death. J Biol Chem 2005; 280: 20722-20729.

28. Karwatowska-Prokopczuk E, Nordberg JA, Li HL, Engler RL, Gottlieb RA. Effect of vacuolar proton ATPase on $\mathrm{pHi}, \mathrm{Ca}^{2+}$, and apoptosis in neonatal cardiomyocytes during metabolic inhibition/recovery. Circ Res 1998; 82: 1139-1144.

29. Long X, Crow MT, Sollott SJ, O'Neill L, Menees DS, de Lourdes HM et al. Enhanced expression of $\mathrm{p} 53$ and apoptosis induced by blockade of the vacuolar proton ATPase in cardiomyocytes. J Clin Invest 1998; 101: 1453-1461.

30. Steenbergen C, Perlman ME, London RE, Murphy E. Mechanism of preconditioning. Ionic alterations. Circ Res 1993; 72: 112-125.

31. Elmore SP, Qian T, Grissom SF, Lemasters JJ. The mitochondrial permeability transition initiates autophagy in rat hepatocytes. FASEB J 2001; 15: 2286-2287.

32. Xue L, Fletcher GC, Tolkovsky AM. Mitochondria are selectively eliminated from eukaryotic cells after blockade of caspases during apoptosis. Curr Biol 2001; 11: 361-365.

33. Griffiths EJ, Halestrap AP. Protection by cyclosporin A of ischemia/reperfusion-induced damage in isolated rat hearts. J Mol Cell Cardiol 1993; 25: 1461-1469.

34. Hausenloy DJ, Duchen MR, Yellon DM. Inhibiting mitochondrial permeability transition pore opening at reperfusion protects against ischaemia-reperfusion injury. Cardiovasc Res 2003; 60: 617-625.

35. Baines CP, Kaiser RA, Purcell NH, Blair NS, Osinska H, Hambleton MA et al. Loss of cyclophilin $D$ reveals a critical role for mitochondrial permeability transition in cell death. Nature 2005; 434: 658-662.

36. Tsuchida A, Liu Y, Liu GS, Cohen MV, Downey JM. alpha 1-adrenergic agonists precondition rabbit ischemic myocardium independent of adenosine by direct activation of protein kinase C. Circ Res 1994; 75: 576-585. 
37. Sayen MR, Gustafsson AB, Sussman MA, Molkentin JD, Gottlieb RA. Calcineurin transgenic mice have mitochondrial dysfunction and elevated superoxide production. $A m J$ Physiol Cell Physiol 2003; 284: C562-C570.

38. Claycomb WC, Lanson Jr NA, Stallworth BS, Egeland DB, Delcarpio JB, Bahinski A et al. $\mathrm{HL}-1$ cells: a cardiac muscle cell line that contracts and retains phenotypic characteristics of the adult cardiomyocyte. Proc Natl Acad Sci USA 1998; 95: 2979-2984.
39. Campbell RE, Tour O, Palmer AE, Steinbach PA, Baird GS, Zacharias DA et al. A monomeric red fluorescent protein. Proc Natl Acad Sci USA 2002; 99: 7877-7882.

40. Idziorek T, Estaquier J, De BF, Ameisen JC. YOPRO-1 permits cytofluorometric analysis of programmed cell death (apoptosis) without interfering with cell viability. J Immunol Methods 1995; 185: 249-258. 